\title{
A Hybrid Lumped Parameters/Finite Element/Boundary Element Model to Predict the Vibroacoustic Characteristics of an Axial Piston Pump
}

\author{
Shaogan Ye, ${ }^{1,2}$ Junhui Zhang, ${ }^{2}$ Bing Xu, ${ }^{2}$ Wei Song, ${ }^{1}$ and Shiqiang Zhu' \\ ${ }^{1}$ Ocean College, Zhejiang University, Zhoushan 316021, China \\ ${ }^{2}$ State Key Laboratory of Fluid Power and Mechatronic Systems, Zhejiang University, Hangzhou 310027, China \\ Correspondence should be addressed to Junhui Zhang; benzjh@zju.edu.cn
}

Received 10 May 2017; Revised 14 November 2017; Accepted 6 December 2017; Published 28 December 2017

Academic Editor: Nuno M. Maia

Copyright (c) 2017 Shaogan Ye et al. This is an open access article distributed under the Creative Commons Attribution License, which permits unrestricted use, distribution, and reproduction in any medium, provided the original work is properly cited.

Low noise axial piston pumps become the rapid increasing demand in modern hydraulic fluid power systems. This paper proposes a systematic approach to simulate the vibroacoustic characteristics of an axial piston pump using a hybrid lumped parameters/finite element/boundary element (LP/FE/BE) model, and large amount of experimental work was performed to validate the model. The LP model was developed to calculate the excitation forces and was validated by a comparison of outlet flow ripples. The FE model was developed to calculate the vibration of the pump, in which the modeling of main friction pairs using different spring elements was presented in detail, and the FE model was validated using experimental modal analysis and measured vibrations. The BE model was used to calculate the noise emitted from the pump, and a measurement of sound pressure level at representative field points in a hemianechoic chamber was conducted to validate the BE model. Comparisons between the simulated and measured results show that the developed $\mathrm{LP} / \mathrm{FE} / \mathrm{BE}$ model is effective in capturing the vibroacoustic characteristics of the pump. The presented approach can be extended to other types of fluid power components and contributes to the development of quieter fluid power systems.

\section{Introduction}

With the development of our society, the noise, vibration, and harshness (NVH) performances of machinery become more and more important. Many efforts are made to increase the NVH performance of machinery in recent years. In hydraulic fluid power systems, the pump used to convert mechanical energy into fluid power energy is often the main noise source. The pump generated vibration and noise causes many unwanted aspects of pump operation, like faster failure of components, uncomfortable working conditions, and hearing damage of machine operators [1].

The mostly studied pumps are the gear pump and axial piston pump. Gear pump is simple, and it is often used in the power steering systems in automobile. Mucchi et al. analyzed the dynamic behavior of an external gear pump using a lumped-parameter model [2]. Opperwal and Vacca investigated the effects of pump generated pressure ripple on the noise generation of an external gear pump numerically and experimentally [3]. A pump model was established to simulate the vibration and noise propagation from the gear pump by Mucchi et al. [4].

Comparing to the gear pump, axial piston pump is far more complex. Axial piston pumps are equipped in a variety of hydraulic machinery owing to their high compactness, high efficiency, and flexible controllability. The vibration and noise issues are the dominant drawback of axial piston pumps. Many efforts have been attempted to solve the problems. Edge compared the effects of different crosssection grooves on pump generated flow pulsations [5]. A novel design using heavily damped check valve was proposed to reduce the pressure pulsations [6]. Manring and Dong investigated the forces and moments in an axial piston pump utilizing cross-angle [7]. Johansson et al. investigated the vibroacoustic characteristics of an axial piston pump utilizing cross-angle numerically and experimentally [8]. Mehta and Manring proposed a method to reduce the shaft torque ripple of an axial piston pump by continuously controlling the swash 


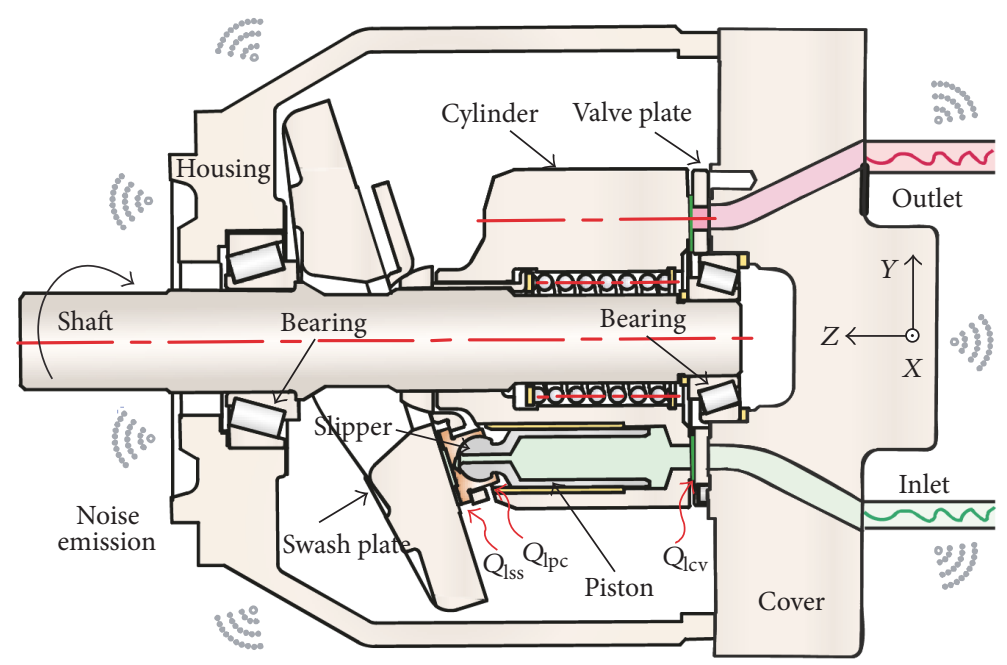

FIGURE 1: Diagram of the axial piston pump.

plate [9]. Manring et al. analyzed the effects of index angle on shaft torque ripple of a tandem axial piston pump [10]. Seeniraj and Ivantysynova optimized valve plate geometry based on multiobjective optimization method considering both noise and efficiency [11]. Mandal et al. analyzed the effects of different silence grooves on the flow pulsation of an axial piston pump and optimized the structure parameters based on the parametric analysis $[12,13]$. However, the noise problem is a systematic behavior. There is a lack of effective approaches, which can effectively assess the vibroacoustic characteristics of axial piston pumps in the design stage.

Therefore, the evaluation of vibration and noise level by a systematic approach is very important, which is able to give an accurate calculation of excitation forces, vibration transmission, and noise emission, for designing quieter axial piston pumps. This paper aims to simulate the vibroacoustic characteristics of an axial piston pump using a systematic approach. A hybrid lumped parameters/finite element/boundary element (LP/FE/BE) model will be developed and the validation of each model will be presented. The remainder of this study offers the following:

(1) A LP model was developed to calculate the excitation forces. The outlet flow ripples were measured to validate the LP model.

(2) A structural FE model was developed to calculate the vibration velocities of the pump with load functions calculated using the LP model. Experimental modal analysis and measurements of vibrations were performed to validate the FE model.

(3) An acoustical BE model was developed to calculate the generated noise with vibrations from the FE model. A measurement of sound pressure level at representative sound field points in a hemianechoic chamber was carried out to validate the BE model.

\section{Methodology}

The studied pump is shown in Figure 1. The shaft is driven by an electrical motor or engine and rotates nearly at a constant revolution speed in normal operating conditions. The cylinder rotates at the same speed with the shaft. The swash plate plane inclines several degrees in the $Y Z$ plane. The pistons execute sinusoidal motions along $Z$ direction because of the inclination of swash plate plane as well as rotational motions around $Z$ axis.

During normal operation, the pressure in the piston chamber varies between low and high values according to the position of piston. The variations of piston chamber pressure from low level to high level and vice versa result in large amount of forces and moments acting on the swash plate, valve plate, and bearings. All these forces and moments are transmitted to the housing and cover. In consequence, the housing and cover vibrate and emit loud noise.

In addition, many lubrication gaps are designed to avoid directly metal-to-metal contact, the lubrication gaps between the slippers and swash plate, between the pistons and cylinder bores, and between the cylinder and valve plate. Leakages occur because of large pressure differences in these lubrication gaps, and the leakage flows affect the pressure in the piston chamber. Besides, the fluid film in the lubrication interfaces affects the transmission of excitation forces. Therefore, the effects of leakages on the pressure build-up and their effects on the transmission of excitation forces should be considered. In this study, traditional equations were adopted to model the leakages across the slipper/swash plate interface, the piston/cylinder interfaces, and the cylinder/valve plate interface as described in the earlier studies $[14,15]$.

The vibroacoustic characteristics of axial piston pumps are difficult to be predicted due to the complexity of the generation and transmission of excitation forces in the pump. In order to model the vibroacoustic characteristics of the pump, a systematic methodology combining the lumped 


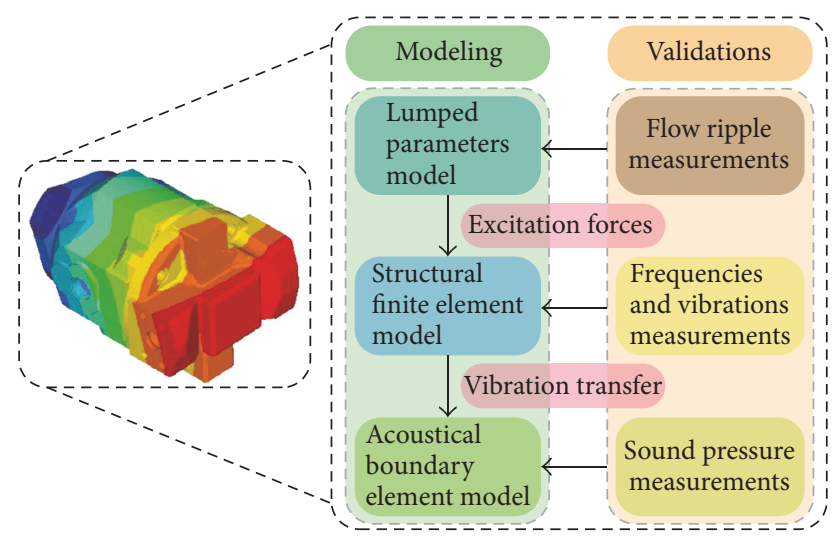

FIgURE 2: Methodology used to predict the vibroacoustic characteristics of the axial piston pump.

parameters, finite element, and boundary element models is presented in this study $[3,4]$. The model can be used to evaluate the excitation forces generated by the pump, the vibrations on the outer surface of different parts (mainly the housing and cover as shown in Figure 1), and the sound pressures at sound field points surrounding the pump at different operating conditions.

The systematic approach for the modeling effort includes three procedures as shown in Figure 2. Firstly, the excitation forces were obtained using the LP model. Secondly, the vibrations were calculated using the structural FE model with the excitation forces calculated using the LP model. Thirdly, the emitted sound pressure was calculated using the $\mathrm{BE}$ model with the vibrations calculated using the FE model. In addition, four types of measurements were conducted to validate the modeling procedures. The measurements of outlet flow ripples were conducted to validate the LP model, experimental modal analysis and measurements of vibrations were conducted to validate the FE model, and measurements of sound pressures in a hemianechoic room were conducted to validate the $\mathrm{BE}$ model. In the following sections, the detailed descriptions of each model and the validation of each model will be presented.

\section{Lumped Parameters Model and Experimental Validation}

3.1. Excitation Forces. For an axial piston pump, the excitation forces acting on the valve plate and swash plate are the main cause of vibration and noise. According to the kinematic analysis, the force and moments acting on the valve plate are described by

$$
\begin{aligned}
F_{Z 1} & =-\sum_{i=1}^{N} \frac{\pi}{4} d^{2} p_{i}, \\
M_{X 1} & =-\sum_{i=1}^{N} \frac{\pi}{4} d^{2} p_{i} \cdot R \sin \theta_{i}, \\
M_{Y 1} & =\sum_{i=1}^{N} \frac{\pi}{4} d^{2} p_{i} \cdot R \cos \theta_{i},
\end{aligned}
$$

where $F_{Z 1}$ is the force acting on the valve plate, $M_{X 1}$ and $M_{Y 1}$ are the moments acting on the valve plate, $d$ is the diameter of the piston, $p_{i}$ is the pressure in the $i$ th piston chamber, $R$ is the pitch radius, $\theta_{i}$ is the rotational angle of the $i$ th piston, and its definition can be found in Figure 3.

The swash plate inclines several degrees to the $y$-axis as shown in Figure 1. Therefore, the forces and moments acting on the swash plate can be described by

$$
\begin{aligned}
F_{Y 2} & =-\sum_{i=1}^{N} \frac{\pi}{4} d^{2} p_{i} \cdot \tan \beta, \\
F_{Z 2} & =\sum_{i=1}^{N} \frac{\pi}{4} d^{2} p_{i}, \\
M_{X 2} & =\frac{1}{\cos ^{2} \beta} \sum_{i=1}^{N} \frac{\pi}{4} d^{2} p_{i} \cdot R \sin \theta_{i}, \\
M_{Y 2} & =-\sum_{i=1}^{N} \frac{\pi}{4} d^{2} p_{i} \cdot R \cos \theta_{i},
\end{aligned}
$$

where $F_{Y 2}$ and $F_{Z 2}$ are the forces acting on the swash plate, $M_{X 2}$ and $M_{Y 2}$ are the moments acting on the swash plate, and $\beta$ is the inclination angle of the swash plate.

From (1) and (2), it is seen that $F_{Z 2} / F_{Z 1}=-1, F_{Y 2} / F_{Z 1}=$ $\tan \beta, M_{X 2} / M_{X 1}=-1 / \cos ^{2} \beta, M_{Y 2} / M_{Y 1}=-1$. This indicates that the forces and moments on the swash plate can be represented by the force and moments on the valve plate. Therefore, the excitations on the valve plate were used for the purpose of analysis in Section 3.4. It also shows that the excitation forces are determined by the piston chamber pressure. Therefore, an accurate piston chamber pressure is required.

3.2. Lumped Parameters Model. The schematic diagram of the LP model is shown in Figure 3. In the LP model, the piston chamber was regarded as a control volume, and the pressure in the piston chamber was determined by calculating the fluid entering and leaving the control volume, as described by [15]

$$
\frac{\mathrm{d} p}{\mathrm{~d} t}=\frac{K_{\mathrm{e}}}{V_{\mathrm{pc}}}\left(Q_{\mathrm{lp}}-Q_{\mathrm{hp}}-Q_{\mathrm{l}}-\frac{\mathrm{d} V_{\mathrm{pc}}}{\mathrm{d} t}\right),
$$

where $p$ represents the pressure in the piston chamber, $K_{\mathrm{e}}$ represents the bulk modulus of the hydraulic oil, $V_{\mathrm{pc}}$ represents the fluid volume of the piston chamber, $Q_{l p}$ and $Q_{\mathrm{hp}}$ represent the flow rate between the piston chamber and inlet and outlet ports, respectively, and $Q_{1}$ represents the leakage $[14,15]$. In the LP model, the leakages across different friction pairs and the compressibility of the oil were considered as presented in the earlier studies $[14,15]$. Therefore, these are not to be presented here for simplicity.

The LP model is very effective in the analysis of pump dynamics. Using the LP model, the performances such as the efficiency, pressure pulsation, flow ripples, and noise sources can be analyzed. During the simulation, several periods needed to be simulated to allow the model to have good convergence. For obtaining better results, the simulated results were used when the model was convergent. 


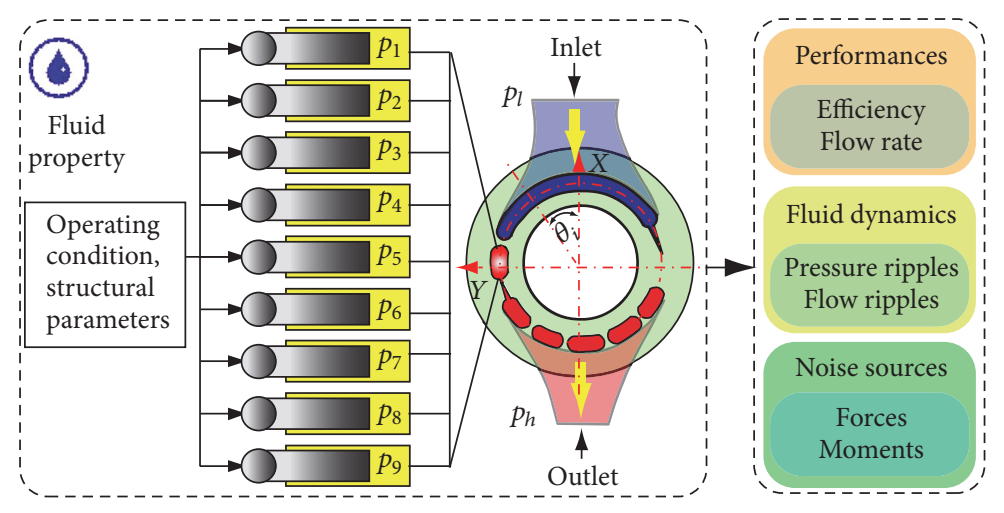

FIgURE 3: Schematic diagram of the LP model.

3.3. Validation of the LP Model. The internal forces and moments in the axial piston pump are very difficult to be measured. The pressure ripple is often used as the parameter to be compared with simulation results $[16,17]$. However, the measured pressure ripple is affected by the pump generated flow ripple and the impedance of hydraulic lines, and the simulated and measured results are usually incomparable. Therefore, several methods have been developed to evaluate and measure the pump generated pressure ripple, which are able to cancel the effects of hydraulic impedances. Among these methods, the secondary source method is an accurate method in measuring the flow ripple and pressure ripple of displacement pumps. The method was adopted by the international organization for standardization as a standard method in 1996 [18].

Based on the method, a test rig was constructed as shown in Figure 4 to measure the flow ripple of the pump. In the test rig, a rigid pipe was directly connected to the pump outlet port having the same inner radius with the radius of the discharge port in the pump flange. Four dynamic pressure transducers were mounted on the rigid pipe with different distances from the pump flange. A throttle valve was used to adjust the discharge pressure. The measurement included two steps. The impedance of the pump was calculated in the first step, and the flow ripple was calculated in the second step. During the measurement, the speed and displacement of the tested pump remained nearly the same, and the throttle valve was adjusted to keep the static pressure the same.

Due to the requirement of the method and the limitation of the test rig, the measurements can be carried out at speeds smaller than $1200 \mathrm{r} / \mathrm{min}$. Therefore, the measurements were conducted at $1000 \mathrm{r} / \mathrm{min}$. The simulated and measured flow ripples in frequency domain are shown in Figure 5. The fundamental frequency was $150 \mathrm{~Hz}$. The flow ripples at most of the harmonics agree very well between the simulation and measurement, which implies that the LP model is accurate. Therefore, the excitation forces calculated using the LP model is satisfactory to be used in the hybrid LP/FE/BE model. However, it should be noted that the boundary conditions and operating conditions must be defined according to the actual operating conditions in the LP model. In this study, two LP models were constructed based on the two different

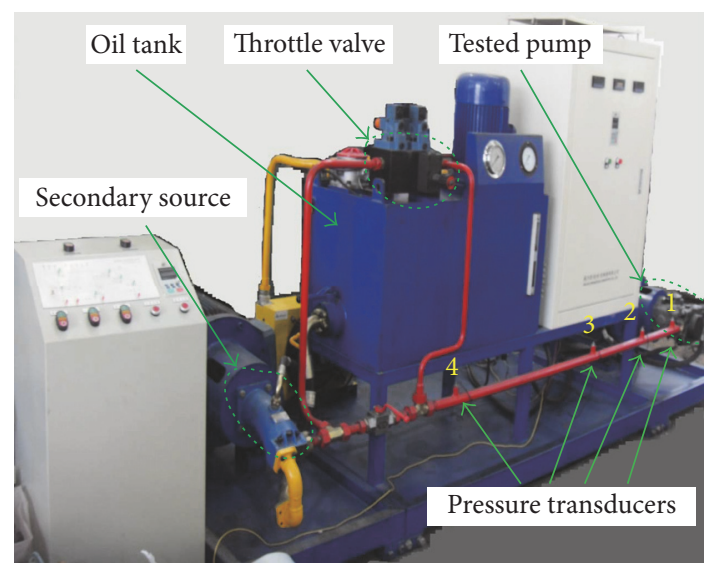

FIGURE 4: Test rig used to measure the flow ripple.

boundary conditions. The LP model used to calculate the flow ripples was constructed according to the test rig presented in Figure 4, whereas the LP model used to calculate the excitation forces was constructed according to the test rig presented in Figure 10.

3.4. Evaluation of Excitation Forces. It is important to evaluate the excitation forces before the calculation of vibration and noise. When the piston chamber pressure is determined using the LP model, the excitation forces can be obtained. The excitation forces at the discharge pressure of $10 \mathrm{MPa}$ are shown in Figure 6. In the figures, the speed was $1500 \mathrm{r} / \mathrm{min}$, the period was $40 \mathrm{~ms}$, and the time interval in the simulation was $1 \times 10^{-5} \mathrm{~s}$. The reason for simulating the excitation forces at $1500 \mathrm{r} / \mathrm{min}$ is that the rated speed of the pump is $1500 \mathrm{r} / \mathrm{min}$, and the vibration and noise will be measured at this speed in Sections 4 and 5. The excitation forces repeat nine times in a period. In the figures, $F_{Z 1}$ varies between around -1.65 $\times 10^{4} \mathrm{~N}$ and $-1.30 \times 10^{4} \mathrm{~N}, M_{X 1}$ varies between $-40 \mathrm{Nm}$ and $80 \mathrm{Nm}$, and $M_{Y 1}$ varies between $-380 \mathrm{Nm}$ and $-368 \mathrm{Nm}$.

For simulating the vibration and noise, the excitation forces in time domain needed to be transformed into frequency domain using fast Fourier transformation (FFT). The amplitudes of the excitation forces at frequencies which are 


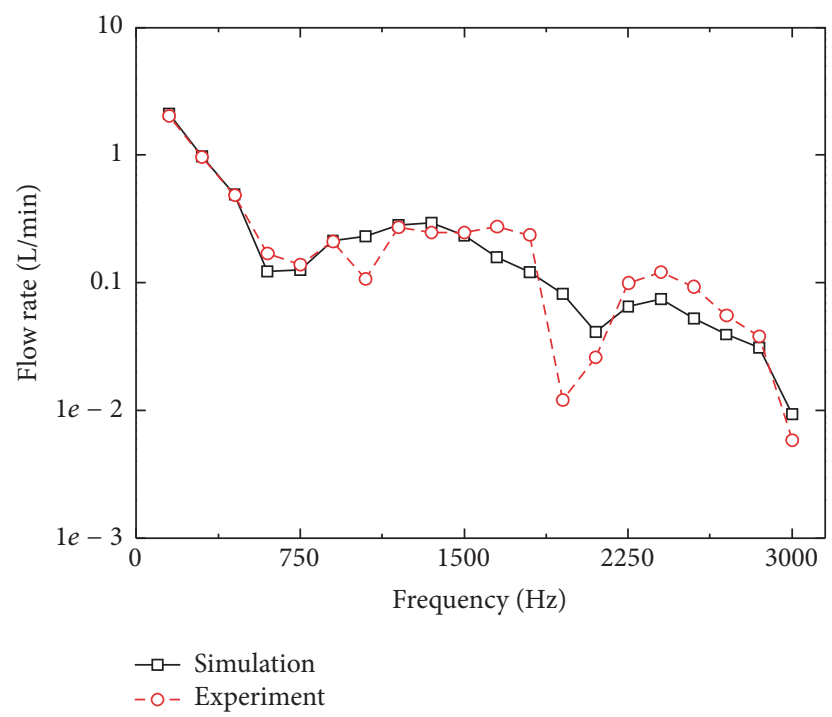

FIGURE 5: Comparisons of the simulated and measured flow ripples in frequency domain.

integral multiple of the fundamental frequency are dominant and they are shown in Figure 7. The fundamental frequency was $225 \mathrm{~Hz}$ because the number of pistons was nine and the speed was $1500 \mathrm{r} / \mathrm{min}$. The frequency ranged from 0 to $1 \mathrm{kHz}$, and the frequency interval was $25 \mathrm{~Hz}$. The figure shows that $F_{Z 1}$ has the largest amplitude at $225 \mathrm{~Hz}$, whereas $M_{X 1}$ and $M_{Y 1}$ have their largest amplitudes at $450 \mathrm{~Hz}$. The amplitudes at other frequencies are smaller. The calculated excitation forces will be imported into the FE model as load functions with their detailed frequencies, amplitudes, and phases in Section 4.

\section{Finite Element Model and Experimental Validation}

4.1. Theory of Modal-Based Forced Response Analysis. Two calculations are performed in the modal-based forced response analysis, the computation of modal participation factors, and modal superposition which multiplies the mode shape values with the modal participation factors. The modal participation factors depend on the scaling of the modes. For general proportional damping with complex modes, the modal participation factors can be determined by

$$
P_{n}(\mathrm{j} \omega)=\frac{1}{m_{n}}\left(\frac{1}{\lambda_{n}^{2}-\omega^{2}}\right)\left\{\psi_{n}\right\}^{T}\{F(\mathrm{j} \omega)\},
$$

where $m_{n}$ is the modal mass of the $n$th mode shape, $\lambda_{n}$ is the complex pole of the $n$th mode, $\omega$ is the angular velocity of the excitation force, $\left\{\psi_{n}\right\}$ is the $n$th mode shape, $\mathrm{j}$ is the complex number, and $\{F(\mathrm{j} \omega)\}$ is the excitation forces.

The forced response of the structure is a superposition of the modes, as expressed by

$$
\{\mathbf{u}(\mathrm{j} \omega)\}=\sum_{n=1}^{N}\left\{\psi_{n}\right\} P_{n}(\mathrm{j} \omega),
$$

where $N$ is the total number of interested modes.
The velocity can be calculated by differentiating the displacement, as described by

$$
\{\mathbf{v}(\mathrm{j} \omega)\}=\mathrm{j} \omega\{\mathbf{u}(\mathrm{j} \omega)\} .
$$

4.2. Description of Structural Finite Element Model. The structural FE model of the pump regards main parts in the axial piston pump, including the housing, cover, and the rotating group. The FE model was developed based on the actual pump, and its layout was the same as it was during the experimental measurement for validating purpose as shown in Figure 8. The details of the FE model are shown in Table 1. The parts were divided into three different groups according to their materials. The materials of housing and cover are malleable cast iron. The nine pistons, cylinder, valve plate, swash plate, end plate, and shaft are made of carbon steel. The nine slippers are made of bronze alloy. The material properties including the density, Young's modulus, and Poisson's ratio for the carbon steel are $7858 \mathrm{~kg} / \mathrm{m}^{3}, 2.07$ $\times 10^{11} \mathrm{~N} / \mathrm{m}^{2}$, and 0.27 , respectively, and they are $7120 \mathrm{~kg} / \mathrm{m}^{3}$, $1.69 \times 10^{11} \mathrm{~N} / \mathrm{m}^{2}$, and 0.286 for the malleable cast iron, and $7400 \mathrm{~kg} / \mathrm{m}^{3}, 1.15 \times 10^{11} \mathrm{~N} / \mathrm{m}^{2}$, and 0.30 for the bronze alloy. All parts were meshed using tetrahedral element with a size of $4 \mathrm{~mm}$, and the qualities of the meshes all satisfied the requirement. The numbers of nodes and elements of each part are presented in Table 1 . The total numbers of nodes and elements are about 119563 and 376779, respectively.

When the FE model of each part was prepared, the FE model of the axial piston pump can be constructed by assembling all the parts. Different kinds of spring elements should be defined to model the connection between different parts, including the connections between the swash plate and housing, the shaft and housing, the slippers and swash plate, the pistons and cylinder, the cylinder and valve plate, and the shaft and cover. In order to define clearly the spring elements, the six degrees of freedom (DOFs) are assumed to be $X, Y, Z, R X, R Y$, and $R Z$. $X, Y$, and $Z$ represent the three translational DOFs, and $R X, R Y$, and $R Z$ represent the three rotational DOFs. Before defining the spring element, the connecting nodes for different parts are required. Multipoint constraint (MPC) was used to define the relationship between the connecting node and the corresponding surrounding nodes. The connecting node was defined as the master node and the surrounding nodes were defined as the slave nodes as shown in Figure 8. Using MPCs, the displacement of the master node is calculated by interpolating the displacements of the slave nodes. The spring elements CELAS1 or CBUSH were used to connect the master nodes, respectively, and the properties of CELAS1 and CBUSH were defined by PELAS and PBUSH using different stiffness matrixes, respectively.

The definitions of the DOFs of the spring elements are presented here. The swash plate is supported by thrust bearings, which allows the swash plate to rotate around its rotational axis, and the other five DOFs are limited. Therefore, the stiffness for the five DOFs must be defined. The shaft is supported by two bearings. The bearings allow the shaft to rotate around its rotational axis, and the other five DOFs are limited, and their stiffness should be defined. The slippers are supported by the swash plate, and their stiffness is defined in the 


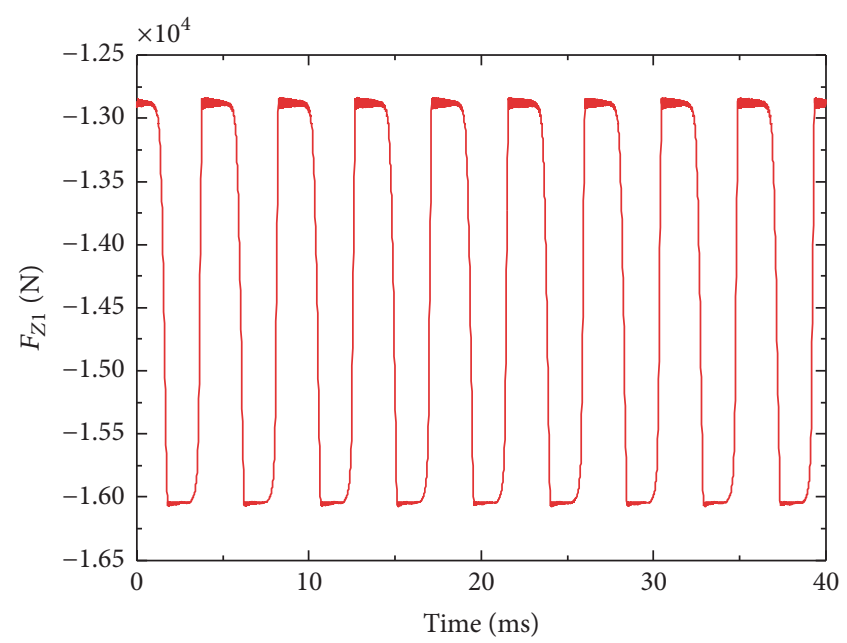

(a)

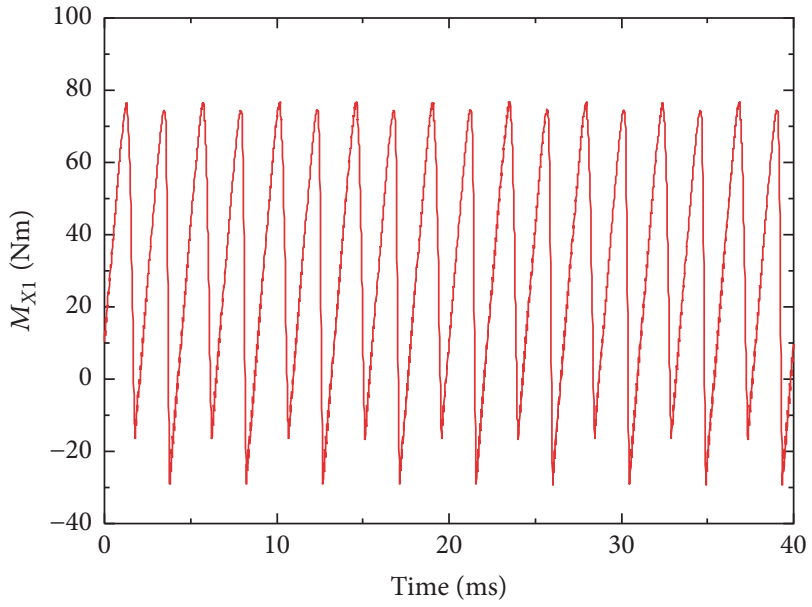

(b)

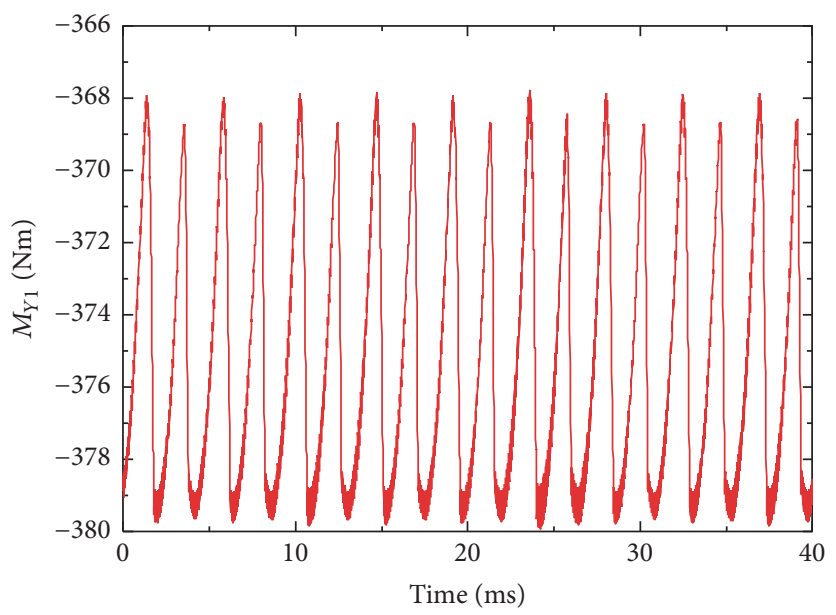

(c)

FIGURE 6: Variations of $F_{Z 1}, M_{X 1}$, and $M_{Y 1}$ in time domain.

TABLE 1: Detailed information of the structural FE model.

\begin{tabular}{lcccc}
\hline Number & Part name & Material & Node number & Element number \\
\hline 1 & Housing & Malleable cast iron & 28099 & 113570 \\
2 & Cover & & 21526 & 93376 \\
\hline 3 & Pistons & & $9 \times 419$ & $3 \times 1205$ \\
4 & Cylinder & Carbon steel & 53326 & 31022 \\
5 & Valve plate & & 5238 & 21201 \\
6 & Swash plate & & 915 & 1261 \\
7 & End-plate & & 3951 & 1651 \\
8 & Shaft & Bronze alloy & $9 \times 164$ & $9 \times 438$ \\
\hline 9 & Slippers & &
\end{tabular}

local coordinate system. The pistons are located in the cylinder holes, and the fluid film between the pistons and cylinder limited the motion of the pistons. The fluid film between the cylinder and valve plate supports the cylinder. The cylinder can rotate around its rotational axis, and the stiffness for the other DOFs is defined. By the properly defined stiffness matrix, the FE models of different parts were assembled.
As the FE model of the pump was completed, the modal analysis was performed, and the natural frequencies and mode shapes of the pump can be calculated. In addition, the acting points for the excitation forces were defined in order to perform the modal-based forced response analysis. In this study, two acting points were defined, the one at the centre of the valve plate (P1) and the other one at the centre of the swash 


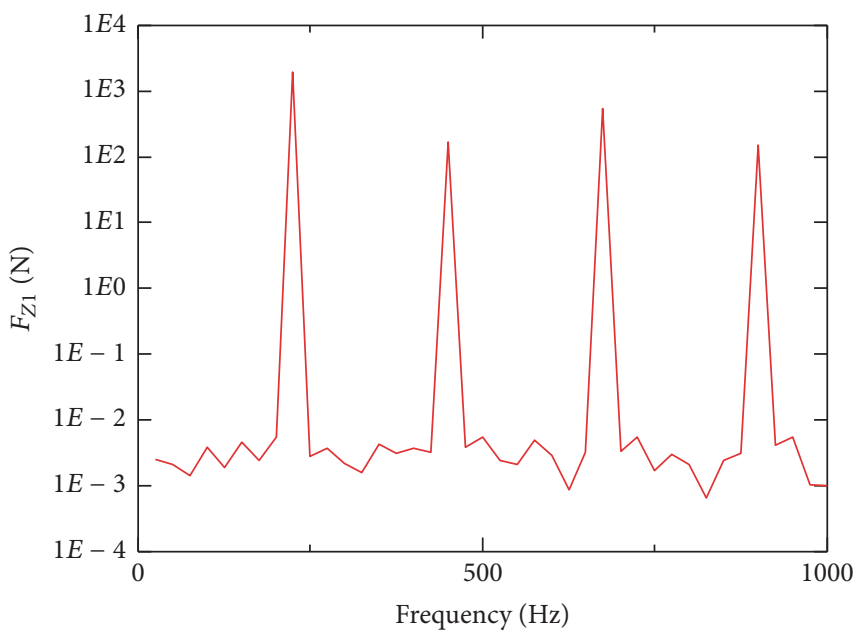

(a)

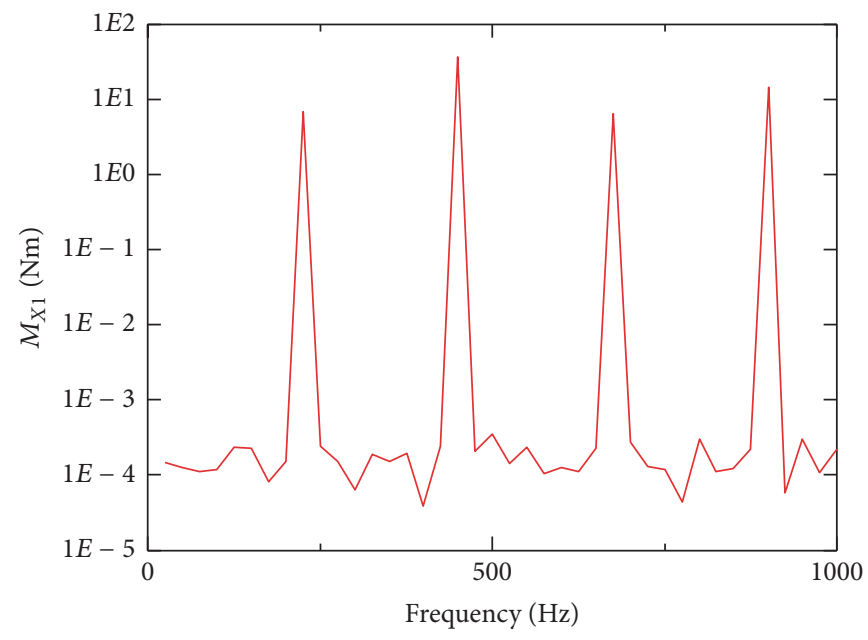

(b)

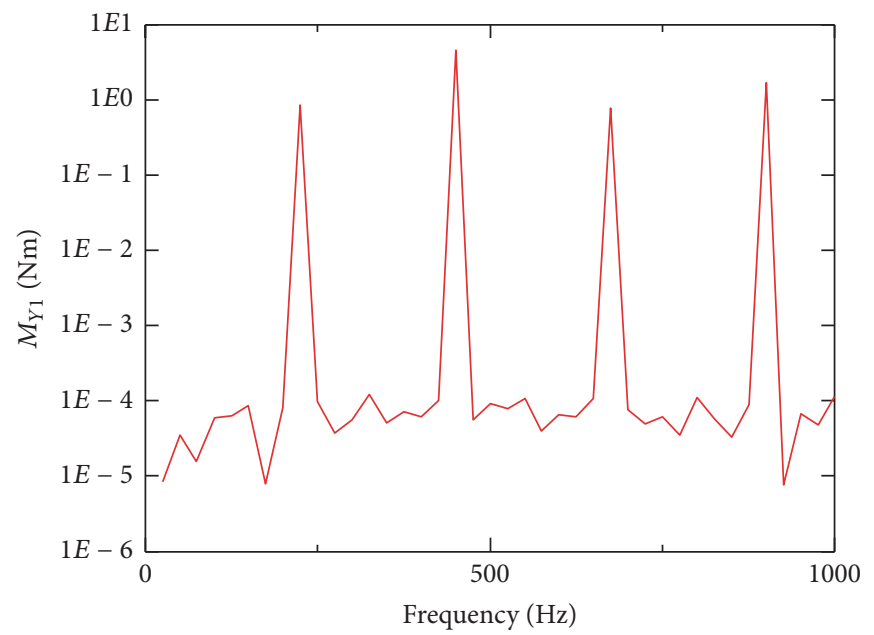

(c)

FIGURE 7: Variations of $F_{Z 1}, M_{X 1}$, and $M_{Y 1}$ in frequency domain.

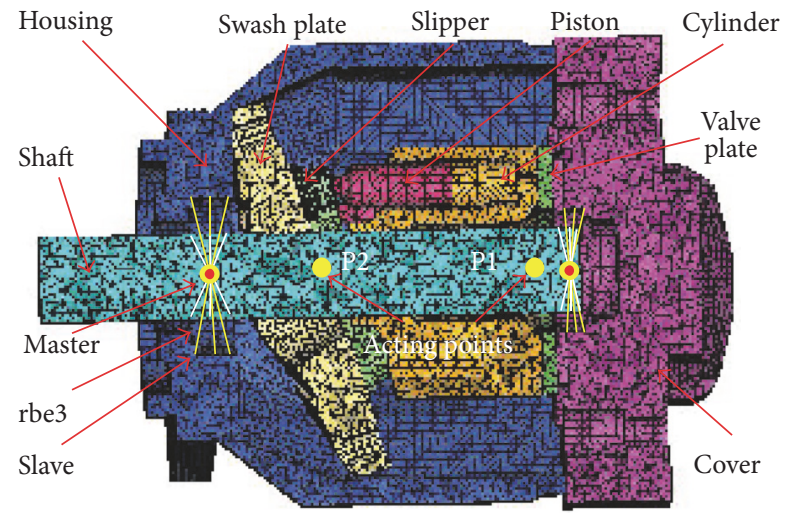

FIGURE 8: Structural finite element model of the axial piston pump.

plate (P2) as can also be seen in Figure 8. The interpolation spider elements were used to connect the acting points with the surrounding elements. $F_{Z 1}, M_{X 1}$, and $M_{Y 1}$ were attached to $\mathrm{P} 1$, and $F_{Y 2}, F_{Z 2}, M_{X 2}$, and $M_{Y 2}$ were attached to $\mathrm{P} 2$.
The modal-based forced response analysis was conducted in the frequency range of interest for obtaining the vibration velocity. In this study, the frequency ranged from $225 \mathrm{~Hz}$ to $900 \mathrm{~Hz}$ with an interval of $225 \mathrm{~Hz}$. The global structural damping was set to be $5 \%$.

4.3. Experimental Modal Analysis and Validation. The experimental modal analysis was carried out to measure the natural frequencies of the pump as shown in Figure 9, and the simulated and measured natural frequencies are compared. The external surfaces of the pump have been painted with yellow color. The impact testing method was used. During the measurement, three excitation points were constructed, and the accelerometer (Brüel and Kjær, 4507-B-001) was attached to one fixed point. An impact hammer (Brüel and Kjær, 8206-002) was used to excite each excitation point each time. The force transducer (integrated into the hammer) recorded the excitation force, and the accelerometer collected the acceleration. The frequency response function (FRF) can be calculated using the recorded excitation forces and collected 

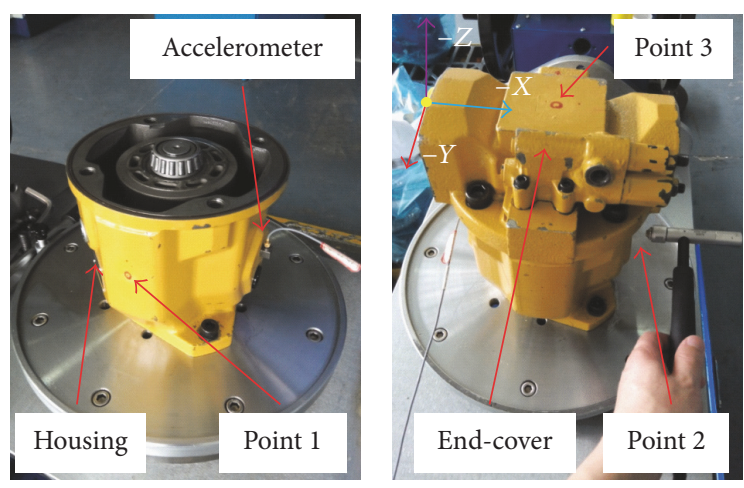

Figure 9: Experimental apparatus used to measure the natural frequencies of the pump.

TABLE 2: Comparisons of simulated and measured natural frequencies.

\begin{tabular}{lccc}
\hline \multirow{2}{*}{ Number } & \multicolumn{2}{c}{ Frequency $(\mathrm{Hz})$} & \multirow{2}{*}{ Error $(\%)$} \\
\hline 1 & Simulated & Measured & \\
2 & 998.5 & 960.6 & -3.9 \\
3 & 1042.1 & 1034.2 & -0.8 \\
4 & 1680.5 & 1747.4 & 3.8 \\
5 & 2118.5 & 2098.4 & -1.0 \\
\hline
\end{tabular}

acceleration signals. The material of the hammer head is aluminum. The excitation process was repeated five times. An averaged FRF was obtained by linearly averaging the five measured FRFs.

Two procedures are required to obtain the modal characteristics: data acquisition during the impact testing and data interpretation after the impact testing. The data acquisition device was LANXI-3050-A-060 (Brüel and Kjær) with six channels. The software used was PULSE 14.1, the frequency range was $0-3200 \mathrm{~Hz}$, and the frequency resolution was $1 \mathrm{~Hz}$. The exponential window was used to reduce the leakage of signal. Then the modal characteristics can be determined by interpreting the measured FRFs in ME'Scope. The simulated and measured five main natural frequencies for the pump are shown in Table 2. It shows that all the errors between the simulated and measured natural frequencies are within 5\%, which indicates that the FE model is accurate enough to be used in engineering practice.

4.4. Vibration Measurement and Validation. The vibrations were also measured. The measurement was conducted in a hemianechoic chamber built to the requirement of ISO 4412-1 [19], in which the sound pressure will be accurately measured. This section describes the required information to measure the vibrations, and the information relating to the measurement of sound pressure will be presented in Section 5.2. Figure 10 shows the picture and schematic diagram of the hydraulic system, and Table 3 shows the specifications. The electrical motor used to drive the pump and the components in the hydraulic system were placed in one separate room as shown in Figure 10(a). A pressure relief valve was used to regulate the discharge pressure. The electrical motor and load valves were isolated from the hemianechoic chamber to eliminate the effects of their noise on reducing the measurement accuracy. A cardan shaft was used to transmit the torque to the pump, with a hook joint at the motor end and a coupling at the pump end.

The layout of the accelerometers mounted on the external surface of the pump is shown in Figure 11. It should be noted that the pump used in the measurements of vibrations and sound pressure levels is the same one, and it differs from that one used in the experimental modal analysis. However, the two pumps were of the same type and manufactured by the same company. Therefore, the modal results were valid for both of the two pumps. Besides, it is also noted that the boundary conditions of the test rigs between the experimental modal analysis and the measurement of vibroacoustic characteristics had some differences. These differences were considered in the construction of the FE model for better reflecting the actual conditions. The piezoelectric IEPE accelerometers were used to measure the vibration characteristics of the pump, which were fastened directly to the mounting surface.

For comparing the simulated and measured results, the vibration velocities from 0 to $1000 \mathrm{~Hz}$ are presented. This is enough because the frequency contents of the vibration and noise generated by the pump at frequencies below $1000 \mathrm{~Hz}$ are of large amplitude in this study. The simulated and measured vibration velocities at point 5 at the discharge pressure of $10 \mathrm{MPa}$ are shown in Figure 12. The measured vibrations are a bit larger at integral multiple of the fundamental frequency as compared to the simulated results. The largest amplitude appears at the first harmonic in both the simulated and measured results. There are contents at other frequencies in the measured results, whereas the contents at other frequencies are zero in the simulated results.

\section{Boundary Element Model and Experimental Validation}

It is not enough to evaluate the vibroacoustic characteristics of the axial piston pump by merely analyzing its vibrations. The emitted sound pressure is of great importance, because it is the cause of uncomfortable feelings and hearing damage of machine operators. Therefore, the evaluation of the sound pressure further is necessary.

5.1. Description of Acoustical Boundary Element Model. In order to analyze the noise emitting from the pump, the exterior surface around the pump was meshed (as shown in Figure 13) such that the vibrations coming from the structural FE model can be transferred to the acoustical BE model. The acoustical model was build based on the actual pump in the hemianechoic room. One reflecting plane on the bottom was defined. Five sound field points were defined according to ISO 3745-2003 [20]. The size of the acoustical element was $4 \mathrm{~mm}$. The numbers of nodes and elements are 17055 and 17511 , respectively. The density of the air is $1.29 \mathrm{~kg} / \mathrm{m}^{3}$, and 
TABLE 3: Details description of the components in the hydraulics system.

\begin{tabular}{lcc}
\hline Number & Description & Detail \\
\hline 1 & Inlet pressure sensor & NS-I1, 0-10 bar, accuracy 0.3\% FS \\
2 & Inlet temperature sensor & SBWR/Z, range $-25-120^{\circ} \mathrm{C}$, accuracy $0.25 \% \mathrm{FS}$ \\
3 & Electric motor & Y315L2-2, speed range 300-298 rpm \\
4 & Shaft speed sensor & JC2C, range $0-4000 \mathrm{rpm}$, accuracy $\pm 1 \mathrm{rpm}$ \\
5 & Shaft torque sensor & JC2C, range $0-2000 \mathrm{Nm}, 0.2 \mathrm{class}$ accuracy \\
6 & Outlet pressure sensor & NSI1, range $0-400 \mathrm{bar}$, accuracy $0.3 \% \mathrm{FS}$ \\
7 & Outlet flow meter & LC-A50, range $0-400 \mathrm{~L} / \mathrm{min}, 0.2 \mathrm{class}$ accuracy \\
8 & Pressure relief valve & DBDH6P1X400 \\
9 & Test pump & Displacement $71 \mathrm{~cm}^{3} / \mathrm{r}$ \\
\hline
\end{tabular}

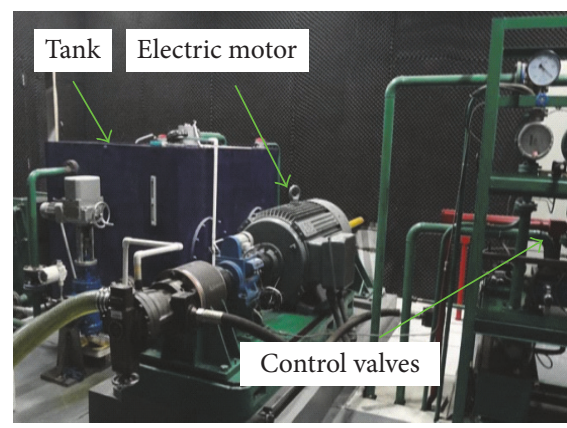

(a) Pictures of hydraulic system

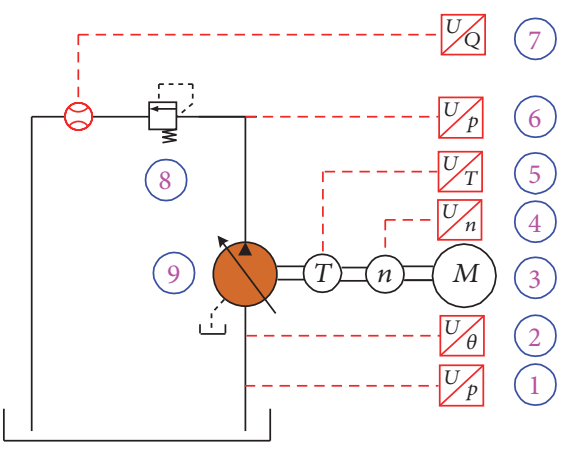

(b) Schematic diagram of hydraulic system

Figure 10: Hydraulic system used to drive the pump.

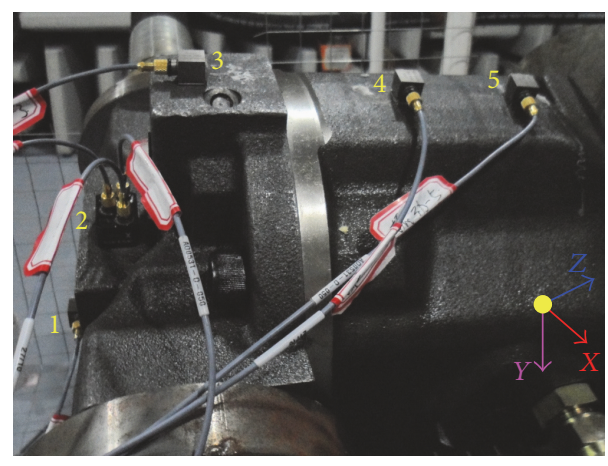

FIGURE 11: Layout of accelerometers on the pump external surface.

the speed of sound is $340 \mathrm{~m} / \mathrm{s}$ because the temperature was around $15^{\circ} \mathrm{C}$.

The mesh mapping process was performed by using interpolation algorithms. The process links the structural model nodes with the acoustical model nodes, such that the vibration velocities calculated at the structural nodes can be used for the acoustical analysis. The normal velocities $\mathbf{v}_{n}(j \omega)$ on the acoustic model are used as boundary conditions for acoustic response analysis, which can be given by

$$
\mathbf{v}_{n}(\mathrm{j} \omega)=[T]\{\mathbf{v}(\mathrm{j} \omega)\},
$$

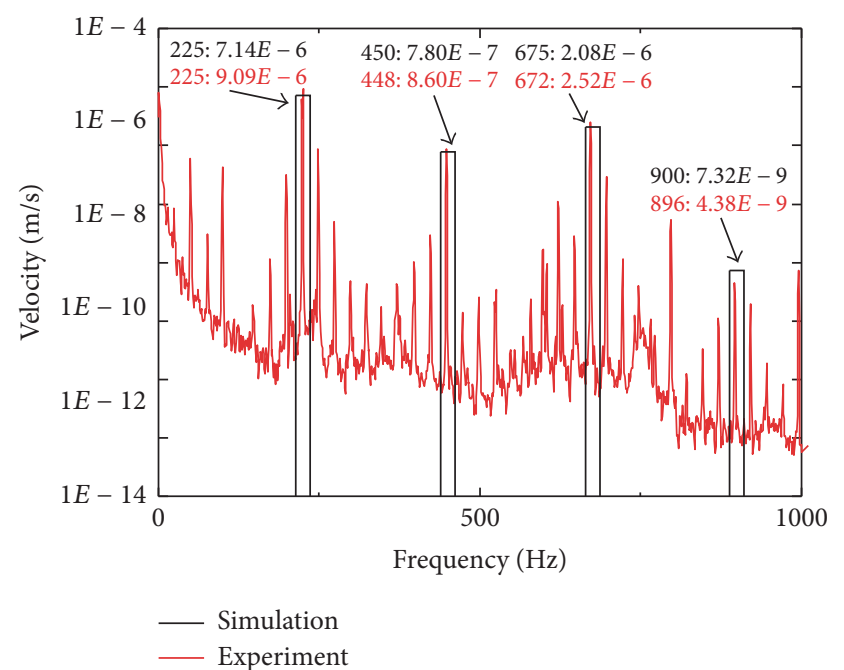

FIGURE 12: Comparisons of simulated and measured vibration velocities.

where $[T]$ is the overall transfer matrix, $\mathbf{v}(\mathrm{j} \omega)$ is determined using the FE model, and the mess mapping procedure transfers the velocity vector to the acoustical model.

5.2. Sound Pressure Measurement and Validation. The sound pressure levels at several sound field points were measured in the hemianechoic chamber as shown in Figure 14. The 


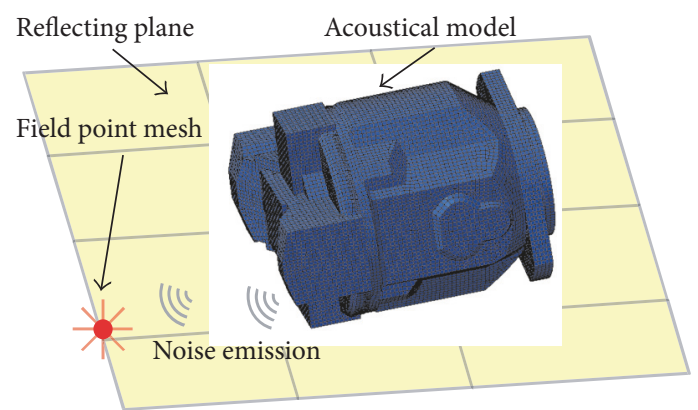

Figure 13: Acoustical boundary element model.

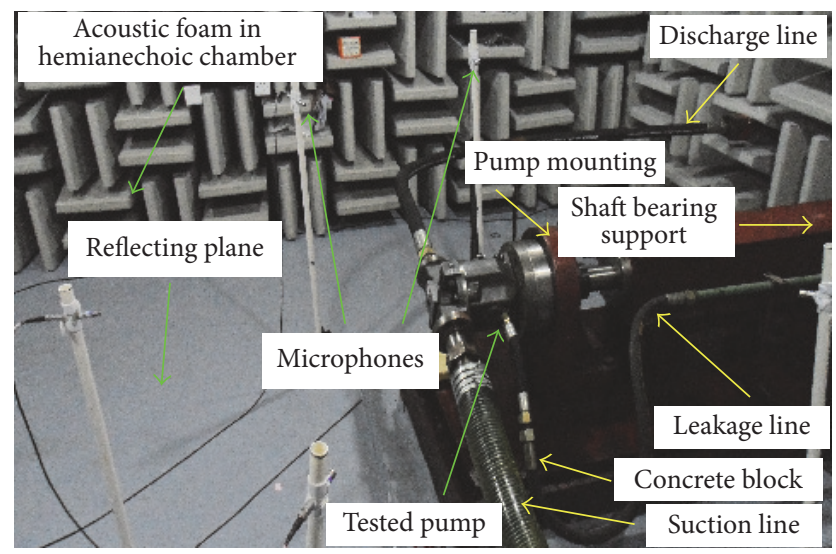

FIgURE 14: The tested pump in the hemianechoic chamber.

interior clear dimensions of the hemianechoic chamber are $5.1 \times 4.4 \times 2.6 \mathrm{~m}$ (length, width, and height) with a minimum background noise of $11.4 \mathrm{~dB}$ and a lowest measurable frequency of $25 \mathrm{~Hz}$. The test arrangement keeps the pump being placed at the centre of the reflecting plane. The pump mounting and drive shaft support bearing were mounted on massive concrete blocks. This can make the pump and shaft structurally isolated from the floor, to prevent vibrations from exciting the whole building.

The suction, discharge, and leakage lines were all flexible hoses. It is noticed that these components are not treated with acoustic claddings. Therefore, the noise emitting from these lines also reaches the microphones. In addition, no acoustic cladding treatments have been done to the shaft support. The noise emitting from the shaft and bearing can reach the microphones as well, even though it is noticed that noise emitted from these components is smaller than that emitted from the pump in this study. Therefore, the measured sound pressure can be assumed to be generated by the pump.

The positions of microphones were defined according to ISO 3745-2003 assuming there is one reflecting plane in the sound free field [20]. The error of the microphones (Brüel and Kjær type 4189-A-021) was $0.2 \mathrm{~dB}$, with a measurable frequency range $6-20000 \mathrm{~Hz}$. All the microphones were calibrated with Brüel and Kjær type 4231 sound calibrator.

The simulated and measured sound pressure levels are shown in Figure 15. The figure shows the first four harmonics, from $225 \mathrm{~Hz}$ (1st harmonic) to $900 \mathrm{~Hz}$ (4th harmonic). There

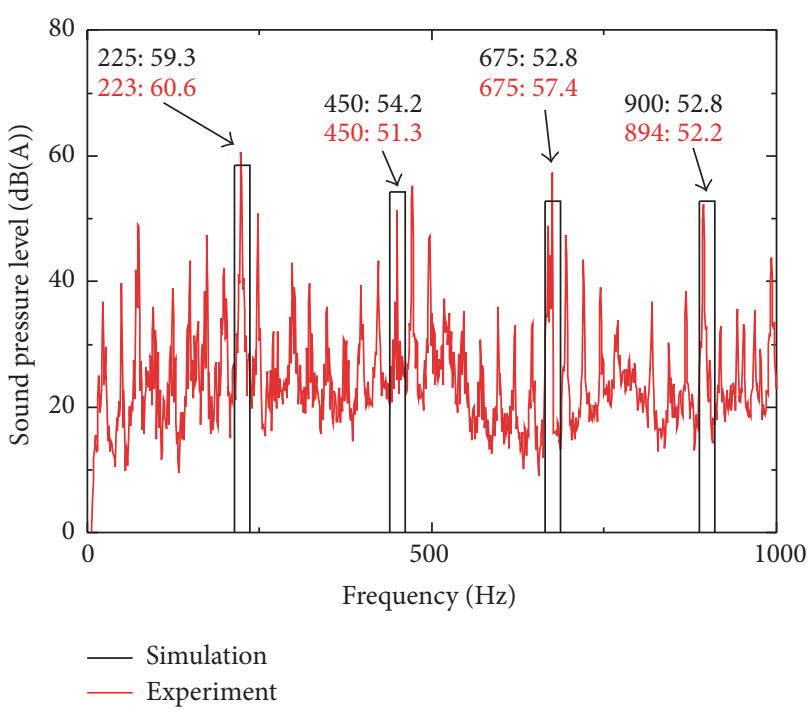

FIGURE 15: Comparisons of simulated and measured sound pressure level.

are slight discrepancies between the simulated and measured results. The measured sound pressure levels have their frequency contents at other frequencies and so are the measured vibrations as shown in Figure 12, whereas the frequency contents at other frequencies are zero for the simulated results. This is because the simulated excitation forces only have their frequency contents at integral multiple of the fundamental frequency. However, this has no effects on the global acoustic characteristics because the peaks at harmonics dominated. The figures also show that the simulated vibration and noise are smaller than the measured results at most of the harmonics. This is because much more factors contribute to the vibration and noise in the measurement than in the simulation. In spite of the deficiencies, good agreements between the simulated and measured results are observed. At the first harmonic, the simulated and measured sound pressure levels are $59.3 \mathrm{~dB}(\mathrm{~A})$ and $60.6 \mathrm{~dB}(\mathrm{~A})$, respectively. The differences between the simulated and measured results at the first harmonic are only $1.3 \mathrm{~dB}(\mathrm{~A})$. Therefore, the model is able to capture the vibroacoustic characteristics of the axial piston pump and can be used in the evaluation of pump performance in the design stage.

\section{Conclusions}

This study developed a hybrid lumped parameters/finite element/boundary element ( $\mathrm{LP} / \mathrm{FE} / \mathrm{BE})$ model to predict the vibroacoustic characteristics of an axial piston pump. In the LP model, the oil compressibility and leakages across different friction pairs were considered. A test rig has been built to validate the LP model by a comparison of outlet flow ripples. A structural finite element model has been built on the basis of the actual pump for calculating the pump's natural frequencies and mode shapes. Experimental modal analysis has been performed to validate the FE model. A forced response analysis has been conducted for calculating 
the vibration characteristics of the pump with load functions calculated by the LP model. The vibration of the pump at representative points has been measured to validate the FE model. The acoustical response analysis has been conducted with an acoustical boundary element model. A measurement of sound pressure level in a hemianechoic chamber was carried out to validate the $\mathrm{BE}$ model. The results showed that the proposed LP/FE/BE model is effective in modeling the vibroacoustic characteristics of the pump, and the LP/FE/BE model provides an effective method to design quieter axial piston pumps and other kinds of fluid power components.

\section{Conflicts of Interest}

The authors declare that there are no conflicts of interest regarding the publication of this paper.

\section{Acknowledgments}

This project was supported by the National Basic Research Program of China (Grant no. 2014CB046403), the National Nature Science Fund of China (Grant no. 51705451), and China Postdoctoral Science Foundation (Grant no. 2017M611982). The authors would like to thank Professor Shumei Chen in Fuzhou University, for providing the experimental facilities in the measurement of vibrations and sound pressure levels.

\section{References}

[1] W. Zhao, Z. Wang, J. Ma, and L. Li, "Fault diagnosis of a hydraulic pump based on the CEEMD-STFT time-frequency entropy method and multiclass SVM classifier," Shock and Vibration, vol. 2016, Article ID 2609856, pp. 1-8, 2016.

[2] E. Mucchi, V. Venturi, and G. Dalpiaz, "A hybrid LP/FE model for the dynamic analysis of external gear pumps," in Proceedings of the ASME 2007 International Mechanical Engineering Congress and Exposition, IMECE 2007, pp. 1523-1532, Seattle, Wash, USA, November 2007.

[3] T. Opperwall and A. Vacca, "A combined FEM/BEM model and experimental investigation into the effects of fluid-borne noise sources on the air-borne noise generated by hydraulic pumps and motors," Proceedings of the Institution of Mechanical Engineers, Part C: Journal of Mechanical Engineering Science, vol. 228, no. 3, pp. 457-471, 2014.

[4] E. Mucchi, A. Rivola, and G. Dalpiaz, "Modelling dynamic behaviour and noise generation in gear pumps: procedure and validation," Applied Acoustics, vol. 77, pp. 99-111, 2014.

[5] K. A. Edge and J. Darling, "Pumping dynamics of swash plate piston pumps," Journal of Dynamic Systems, Measurement, and Control, vol. 111, no. 2, pp. 307-312, 1989.

[6] A. Harrison and K. A. Edge, "Reduction of axial piston pump pressure ripple," Proceedings of the Institution of Mechanical Engineers, Part I: Journal of Systems and Control Engineering, vol. 214, no. 1, pp. 53-63, 2000.

[7] N. D. Manring and Z. Dong, "The impact of using a secondary swash-plate angle within an axial piston pump," Journal of Dynamic Systems, Measurement, and Control, vol. 126, no. 1, pp. 65-74, 2004.
[8] A. Johansson, J. Ölvander, and J.-O. Palmberg, "Experimental verification of cross-angle for noise reduction in hydraulic piston pumps," Proceedings of the Institution of Mechanical Engineers, Part I: Journal of Systems and Control Engineering, vol. 221, no. 3, pp. 321-330, 2007.

[9] V. S. Mehta and N. D. Manring, "Torque ripple attenuation of an axial piston pump by continuous swash plato adjustment," in Proceedings of the 2005 ASME International Mechanical Engineering Congress and Exposition, IMECE 2005, pp. 147-155, Orlando, Fla, USA, November 2005.

[10] N. D. Manring, V. S. Mehta, F. J. Raab, and K. J. Graf, "The shaft torque of a tandem axial-piston pump," Journal of Dynamic Systems, Measurement, and Control, vol. 129, no. 3, pp. 367-371, 2007.

[11] G. K. Seeniraj and M. Ivantysynova, "A multi-parameter multiobjective approach to reduce pump noise generation," International Journal of Fluid Power, vol. 12, no. 1, pp. 7-17, 2011.

[12] N. P. Mandal, R. Saha, and D. Sanyal, “Theoretical simulation of ripples for different leading-side groove volumes on manifolds in fixed-displacement axial-piston pump," Proceedings of the Institution of Mechanical Engineers, Part I: Journal of Systems and Control Engineering, vol. 222, no. 6, pp. 557-570, 2008.

[13] N. P. Mandal, R. Saha, and D. Sanyal, "Effects of flow inertia modelling and valve-plate geometry on swash-plate axialpiston pump performance," Proceedings of the Institution of Mechanical Engineers, Part I: Journal of Systems and Control Engineering, vol. 226, no. 4, pp. 451-465, 2012.

[14] B. Xu, J. Zhang, and H. Yang, "Simulation research on distribution method of axial piston pump utilizing pressure equalization mechanism," Proceedings of the Institution of Mechanical Engineers, Part C: Journal of Mechanical Engineering Science, vol. 227, no. 3, pp. 459-469, 2013.

[15] B. Xu, S. Ye, J. Zhang, and C. Zhang, "Flow ripple reduction of an axial piston pump by a combination of cross-angle and pressure relief grooves: analysis and optimization," Journal of Mechanical Science and Technology, vol. 30, no. 6, pp. 2531-2545, 2016.

[16] P. Casoli, A. Vacca, G. Franzoni, and G. L. Berta, "Modelling of fluid properties in hydraulic positive displacement machines," Simulation Modelling Practice and Theory, vol. 14, no. 8, pp. 1059-1072, 2006.

[17] F.-L. Yin, S.-L. Nie, S.-H. Xiao, and W. Hou, "Numerical and experimental study of cavitation performance in sea water hydraulic axial piston pump," Proceedings of the Institution of Mechanical Engineers, Part I: Journal of Systems and Control Engineering, vol. 230, no. 8, pp. 716-735, 2016.

[18] ISO, "Hydraulic fluid power - determination of pressure ripple levels generated in systems and components - part 1: Precision method for pumps," Tech. Rep. 10767-1:1996, 1996.

[19] ISO, "Hydraulic fluid power - test code for determination of airborne noise levels - part 1: pumps," Tech. Rep. 4412-1:1991, 1991.

[20] ISO, "Acoustics - determination of sound power levels of noise sources using sound pressure - precision methods for anechoic and semi-anechoic rooms," Tech. Rep. 3745:2003, 2003. 


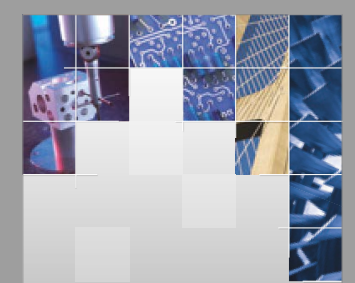

\section{Enfincering}
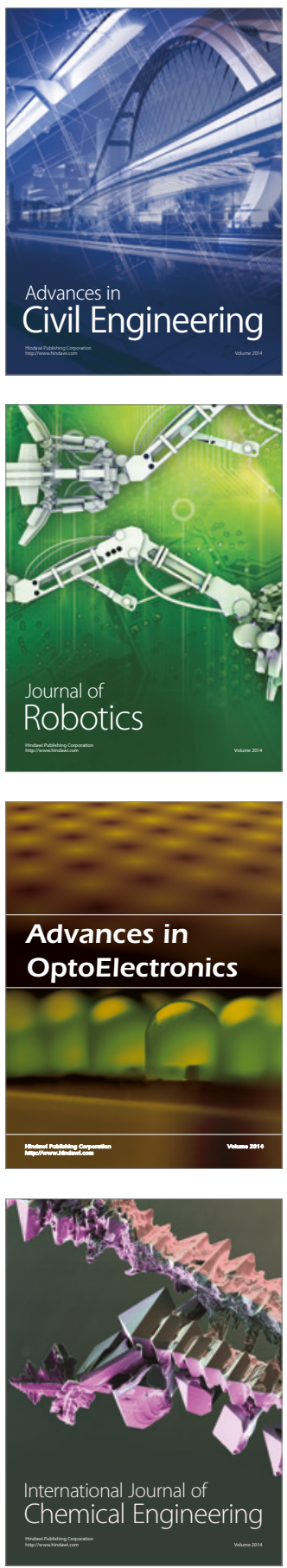

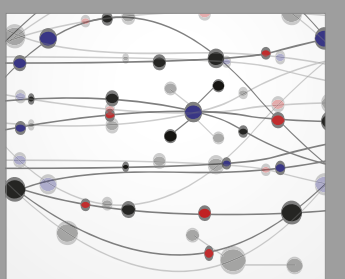

The Scientific World Journal

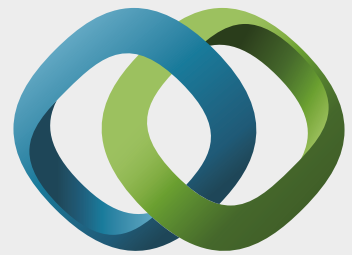

\section{Hindawi}

Submit your manuscripts at

https://www.hindawi.com
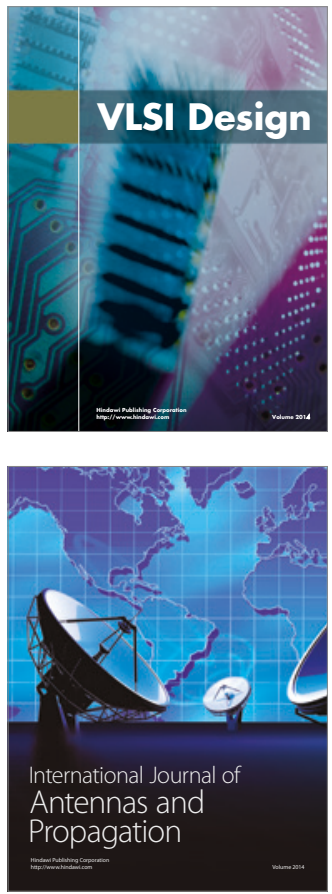

\section{Rotating}

Machinery
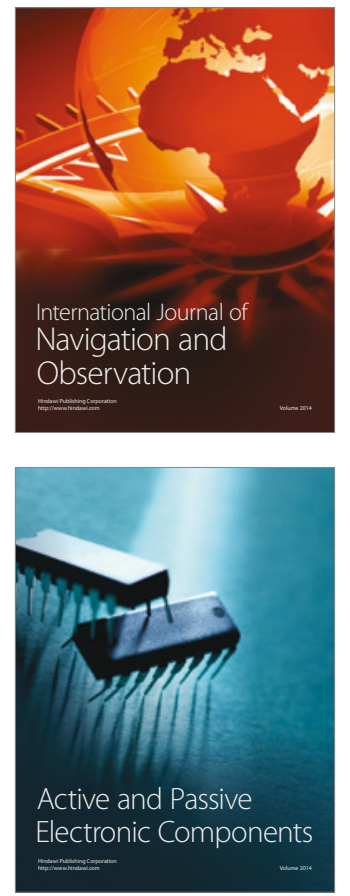
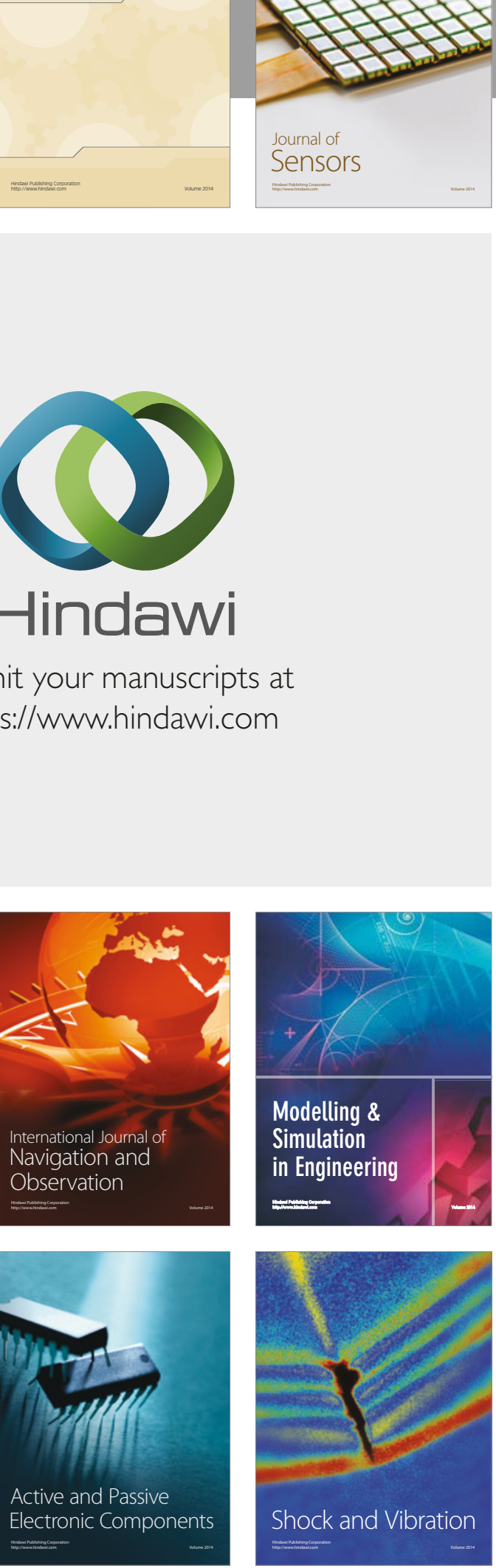
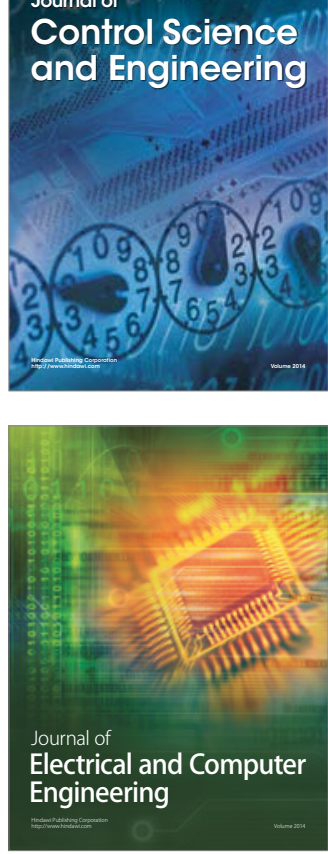

Distributed

Journal of

Control Science

and Engineering
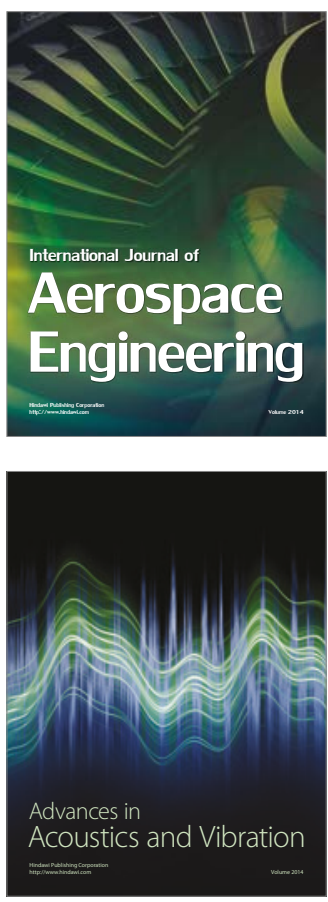

Sensor Networks 